\title{
CRYPTOCURRENCIES AND STOCK MARKET INDICES. ARE THEY RELATED?
}

\author{
Luis Alberiko Gil-Alana
}

University of Navarra, Spain

Emmanuel Joel Aikins Abakah

The University of Adelaide Business School, Australia

\author{
María Fátima Romero Rojo \\ University Francisco de Vitoria, Spain
}

\begin{abstract}
In this paper, we investigate the stochastic properties of six major cryptocurrencies and their bilateral linkages with six stock market indices using fractional integration techniques. From the univariate analysis, we observe that for Bitcoin and Ethereum, the unit root null hypothesis cannot be rejected; for Litecoin, Ripple and Stellar, the order of integration is found to be significantly higher than 1; for Tether, however, we find evidence in favour of mean reversion. For the stock market indices, the results are more homogeneous and the unit root cannot be rejected in any of the series, with the exception of VIX where mean reversion is obtained. Concerning bivariate results within the cryptocurrencies and testing for cointegration, we provide evidence of no cointegration between the six cryptocurrencies. Along the same lines, testing for cointegration between the cryptocurrencies and the stock market indices, we find evidence of no cointegration, which implies that the cryptocurrencies are decoupled from the mainstream financial and economic assets. The findings in this paper indicate the significant role of cryptocurrencies in investor portfolios since they serve as a diversification option for investors, confirming that cryptocurrency is a new investment asset class.
\end{abstract}

Keywords: Cryptocurrencies; stock market indices; fractional integration; fractional cointegration

JEL Classification: G11, G19, G32, C59

Corresponding author:

Prof. Luis A. Gil-Alana

University of Navarra

Faculty of Economics

E-31090 Pamplona, Spain

Phone: +34948 425625

Fax: $\quad+34948425626$

Email: alana@unav.es

* Prof. Luis A. Gil-Alana gratefully acknowledges financial support from the Ministerio de Economía y Competitividad (ECO2017-85503). Comments from the Editor and two anonymous reviewers are gratefully acknowledged. 


\section{Introduction}

Cryptocurrencies are a globally spreading phenomenon that is frequently and also prominently addressed by the media, venture capitalists, financial and governmental institutions alike (Glaser et al., 2014). The recent emergence of cryptocurrencies as a new class of financial assets consequently offers a new opportunity to investigate several as yet unexplored aspects of cryptocurrencies. In empirical finance, the role of cryptocurrency markets has grown rapidly in recent years gaining a lot of attention from among academic scholars, the media, government institutions and the finance industry. The upsurge in cryptocurrencies and rapid development of cryptocurrency markets have been attributed to the recent sharp increase in Bitcoin trading volume leading to a comprehensive literature on cryptocurrency markets (Hileman and Rauchs, 2017). Since Bitcoin was first proposed by Nakamoto (2008), several studies have been conducted on Bitcoin, focusing on market efficiency (Urquhart, 2016; Nadarajah and Chu, 2017; Bariviera, 2017; Vidal-Tomás and Ibañez, 2018), price volatility (Dyhrberg, 2016; Katsiampa, 2017), price clustering (Urquhart, 2017), speculation (Cheah and Fry, 2015) and transaction costs (Kim, 2017). Consequently, the introduction of different kinds of cryptocurrencies in recent years has resulted in the rapid increase of market size of the cryptocurrency markets. Some key studies have examined some cryptocurrencies properties such as market returns and volatility (Omane-Adjepong et al., 2019), herding behaviour in cryptocurrency markets (Bouri, Gupta and Rouband, 2018), portfolio diversification across cryptocurrencies (Liu, 2018), regime shifting models (Mensi, Al-Yahyaeeb and Kang, 2018; Bouri, Gil-Alana, Gupta and Roubaud, 2019; Omane-Adjepong, Alagidede and Akosah, 2019), return-volume relationship (Bouri et al., 2018), or speculation (Yermack, 2015; Blau, 2018).

Recently, a strand of the literature on cryptocurrencies has focused on stylized facts and technical aspects of cryptocurrencies. For example, Katsiampa (2017) and Vandezande (2017) 
conclude that high volatility in cryptocurrencies may be the reason for the high returns in cryptocurrencies. Bariviera et al. (2017) established that cryptocurrencies are characterized by anonymity and are susceptible to speculative bubbles (Cheah and Fry, 2015). According to Yarovaya et al. (2016), the speculative bubbles in the cryptocurrency markets may in turn spread contagion and weaken financial stability. The past few years have also witnessed considerable research concerning the importance of adding cryptocurrency to a portfolio with equity and with other assets classes (Briere et al. 2015; Eisl et al. 2015; Bouri et al. 2017, Omane-Adjepong et al., 2019; Stensas et al., 2019; etc.). Despite the popularity of cryptocurrencies, there are fewer academics works assessing cryptocurrencies from the economic-finance perspective, leading to the conclusion that research on cryptocurrency markets is still in its infancy (Urquhart, 2016). Even though a number of studies have investigated the connectedness between the same type of asset classes (Aftab et al. 2015; Tiwari et al. 2018) and the linkages between different asset classes (Corbet et al. 2018), the scant empirical work addressing connectedness within the cryptocurrencies, and other asset classes, is the motive for this study.

Succinctly, this paper contributes to the literature on cryptocurrency markets and its role in investment finance decisions. Our objective is to provide empirical relations between cryptocurrency markets and other stock market indices to show the patterns of return and volatility transmission among these markets to aid investment decisions. Specifically, we study the stochastic properties of the bilateral linkages between the largest cryptocurrencies and other financial assets. Thus, we contribute to studies that focus on the technical aspects and stylized facts of cryptocurrency markets. We investigate the statistical properties of the cryptocurrencies and the stock market prices from a fractionally integrated viewpoint, testing the degree of persistence for each series using alternative methods. Then, in a multivariate 
framework, we look at bivariate relationships, firstly, with the cryptocurrencies themselves, and then, between the cryptocurrencies and each stock market, in a vis-à-vis relation, testing the degree of integration of such relationships. A study of this nature is crucial for investment decisions since it establishes the patterns of information transmission across cryptocurrency markets and other financial assets. In this work, we discuss the largest investable sample of cryptocurrencies, and conditionally measure some important stylized facts using fractional integration and cointegration methods. To the best of our knowledge, this is the first study to examine stochastic properties of cryptocurrencies using a robust methodology based on fractional integration and cointegration.

We contribute to the literature in two ways. First, we investigate the level of connectedness between cryptocurrencies and other financial assets using fractional integration and cointegration techniques. We provide evidence of no linkages between cryptocurrency markets and stock market indices confirming the findings of Corbet et al. (2018). Our findings show that the cryptocurrency markets are decoupled from the main financial and economic asset class, hence offering diversification benefits to investors. Second, we examine the linkages between the selected cryptocurrencies, again using I(d) methods, and the results confirm that there exist no bilateral linkages between the selected cryptocurrencies, which is not in consonance with the findings of Corbet et al. (2018) who established that cryptocurrencies are connected.

The structure of the paper is as follows: Section 2 provides a brief overview of the cryptocurrency market since its inception in 2009. Section 3 outlines the empirical methodology, while Section 4 documents the data and the main empirical results. In Section 5, we provide some concluding remarks. 


\section{Literature review}

Although Bitcoin can be considered relatively new (from 2008, as mentioned above), the last ten years have witnessed the spectacular development of cryptocurrencies in the market. In fact, a total of 2520 cryptocurrencies were being traded in January 2019 (www.investing.com) with a market capitalization of $\$ 113$ billion. This is partially due to the support of some countries, such as Japan and South Korea, that recognised Bitcoin as a legal method of payment (Bloomberg, 2017; Cointelegraph, 2017), as well as a large number of banks and companies that created the Enterprise Ethereum Alliance (https://entethalliance.org/) to make use of the cryptocurrencies and the related technology called blockchain (Forbes, 2017).

The evolution of Bitcoin and other flowering cryptocurrencies in the market has been analysed in detail during this decade. In particular, from 2013 when the value of Bitcoin increased rapidly from around $\$ 150$ in mid-2013 to over $\$ 1000$ in late 2013 , which is known as the 2013 bubble. Brown (2014) provided evidence of short-term price predictability of the Bitcoin. Gandal and Halaburda (2014) analysed competition in the cryptocurrency market, but most of the researchers focused on the price volatility, showing that this market is more volatile than others (Cheung et al., 2015; Dwyer, 2015; Bouoiyour and Selmi, 2015). In fact, some authors, such as Glaser et al. (2014) and Baek and Elbeck (2015) stated that Bitcoin is mostly used for speculative purpose, due to the extreme volatility and bubbles.

After the Bitcoin price fell dramatically to $\$ 200$ by 2016 , many researchers were interested in analysing the efficiency of the Bitcoin market (Bartos, 2015; Urquhart, 2016) and the negative bubbles and shocks in cryptocurrencies markets by using, among others, econophysical models (Fry and Cheah, 2016). In 2017, things changed abruptly. Bitcoin began rising again and by early 2017 , the value of bitcoin was again more than $\$ 1000$ and reached a 
maximum of more than $\$ 10000$ in December 2017. This phenomenon caused a huge impact in the cryptocurrency market. Feder et al. (2018) analysed in detail the rise and fall of cryptocurrencies, in particular the dynamics of coin creation, competition and destruction in the cryptocurrency industry. They concluded that, unlike the end of the 2013 bubble, some alternative cryptocurrencies continued to flourish after the fall of Bitcoin. In fact, the number of new digital coins increased impressively, from 22 cryptocurrencies in August 2017, to 2520 in January 2019 (www.investing.com). Other authors also analysed the anomalies in cryptocurrency market (Kurihara and Fukushima, 2017; Caporale and Plastun, 2018; Caporale et al., 2018), and the extreme volatility (Dyhrberg, 2016; Corbet et al., 2018, Hafner, 2018). Catania and Grassi (2017) evaluated Bitcoin volatility by using GAS models, and Phillip et al. (2018) used a stochastic volatility model. Bouri et al. (2017) showed, among other things, a negative relation between the US implied volatility index (VIX) and Bitcoin volatility, and Bariviera (2017) tested the presence of long memory in Bitcoin series from 2011 to 2017.

During the last few years, more efforts have been made to analyse the risk-return, volatility and benefits for investors. For example, Corbet et al. (2018) explored the dynamic relationships between cryptocurrencies and other financial assets, showing that cryptocurrencies may offer diversification benefits for investors with short investment horizons. Phillip et al (2018) explored the properties of 224 cryptocurrencies and found that, in general, they have several unique properties including leverage effects and Student- error distributions. Liu and Tsyvinski (2018) established that the risk-return trade-off of cryptocurrencies (Bitcoin, Ripple, and Ethereum) is distinct from those of stocks, currencies, and precious metals. In addition, they created an index of exposures to cryptocurrencies of 354 industries in the US and 137 industries in China. More recently, Kapar and Olmo (2019) suggested that the Bitcoin futures market dominates the price discovery process and found that 
both prices are driven by a common factor that is given by a weighted combination of the futures and spot market. On the other hand, the effects of the geopolitical risks on Bitcoin returns and volatility have been analysed by Aysan et al. (2019), showing that Bitcoin can be considered as a hedging tool against global geopolitical risks.

\section{Empirical methodology}

As mentioned earlier we use techniques based on fractional integration and cointegration (see, Gil-Alana and Hualde, 2009). Fractional integration generalizes the case of unit roots to the fractional case. In other words, a process is said to be integrated of order $d$ if it requires ddifferences to render the series stationary $\mathrm{I}(0)$. The usual value for $\mathrm{d}$ is 1 , and first differencing has become a standard practice to remove the nonstationarity in time series. However, the

number of differences, d, may not necessarily have to be restricted to an integer value (i.e., 0 , 1 or 2) but may be any real value, including thus fractional numbers. Thus, we say that $\left\{\mathrm{x}_{\mathrm{t}}, \mathrm{t}=\right.$ $0, \pm 1, \ldots\}$ is integrated of order $\mathrm{d}$, and denoted as $\mathrm{I}(\mathrm{d})$ if it can be represented as:

$$
(1-L)^{d} x_{t}=u_{t}, \quad t=1,2, \ldots,
$$

where $\mathrm{L}$ is the backshift operator $\left(\mathrm{Lx}_{\mathrm{t}}=\mathrm{x}_{\mathrm{t}-1}\right)$ and $\mathrm{u}_{\mathrm{t}}$ is $\mathrm{I}(0)$ indicating a covariance stationary process with a spectral density function that is positive and bounded at all frequencies in the spectrum. Note that if $u_{t}$ is an $\operatorname{ARMA}(p, q)$ process, $x_{t}$ is then said to be a fractionally integrated ARMA, i.e., ARFIMA(p, d , q) process (Beran, 1994). Thus, it includes the classical ARMA and ARIMA models as particular cases of interest if $d=0$ and 1 respectively. The polynomial $(1-L)^{d}$ in equation (1) can be expressed in terms of its Binomial expansion, such that, for all real d,

$$
(1-L)^{d}=\sum_{j=0}^{\infty}\left(\begin{array}{l}
d \\
j
\end{array}\right)(-1)^{j} L^{j}=1-d L+\frac{d(d-1)}{2} L^{2}-\cdots,
$$

and thus, 


$$
(1-L)^{d} x_{t}=x_{t}-d x_{t-1}+\frac{d(d-1)}{2} x_{t-2}-\cdots
$$

implying that equation (1) can be expressed as

$$
x_{t}=d x_{t-1}-\frac{d(d-1)}{2} x_{t-2}+\cdots+u_{t}
$$

Thus, if $d$ is a fractional value, $x_{t}$ depends on all its past history and the higher the value of $d$ is, the higher the level of dependence between the observations is. Moreover, the differencing parameter $\mathrm{d}$ is quite relevant from different perspectives. Thus, if $\mathrm{d}=0, \mathrm{x}_{\mathrm{t}}$ is short memory or $\mathrm{I}(0)$, while $\mathrm{d}>0$ implies long memory behaviour, so-named because of the strong degree of association between observations far distant in time. ${ }^{1}$ From a statistical viewpoint, 0.5 is another relevant point: if $\mathrm{d}<0.5, \mathrm{x}_{\mathrm{t}}$ is covariance stationary, while $\mathrm{d} \geq 0.5$ implies nonstationarity (in the sense that the variance of the partial sums increases in magnitude with d); finally, from an economic viewpoint $\mathrm{d}=1$ is also relevant: $\mathrm{d}<1$ indicates mean reversion, with shocks disappearing in the long run, while $d \geq 1$ shows a lack of mean reversion with shocks persisting forever.

\section{Data}

In this study, we use a cryptocurrency dataset for the time period from 07-May-2015 to 05October-2018, with 826 trading days in total. We obtained data for cryptocurrencies from cryptocompare.com. We focused on the top six largest cryptocurrencies assets with market capitalisation value over $\$ 1 \mathrm{~b}$ as of end of $5^{\text {th }}$ October 2018 with enough data available to achieve the objective of the study, these being Bitcoin, Ethereum, Ripple, Litecoin, Stellar and Tether. The combined market capitalisation of the selected cryptocurrencies constituted $80.22 \%$ of the top 100 cryptocurrencies by market capitalisation value as at end of $5^{\text {th }}$ October

\footnotetext{
${ }^{1}$ We use a "broad" definition of long memory by saying (in the time domain) that a process is long memory if the infinite sum of the autocovariances (or pseudo-autocovarainces) is infinite. Alternatively, in the frequency domain, a process is long memory if the spectral (or pseudo-spectral) density funtion has at least one pole or singularity in the spectrum. These definitions apply for all $\mathrm{I}(\mathrm{d}, \mathrm{d}>0)$ processes.
} 
2018. For the other traditional assets, a number of strands informed our choice. Corbet et al. (2018) examined the relationships between three popular cryptocurrencies and a variety of financial assets including S\&P 500 Composite, S\&P GSCI Commodity Total Return, VIX, S\&P Bond Index, S\&P GSCI Gold Total Return and US Nominal Dollar Broad Index. With a similar objective, we work with these six major financial asset class with data obtained from DataStream.

Following the non-synchronicity of trading days between the stock markets indices and cryptocurrencies and the objective of the study which is to test for the linkages between the well-known traditional finance and economic asset class and the digital currencies, we synchronised the data and consider trading days from Monday to Friday. We ignore weekend trading days for the digital currencies because, the results remained unchanged when included in the model in estimating the pairwise relationship between the asset class in our sample.

\section{[Insert Table 1 and Figure 1 about here]}

Table 1 and Figure 1 display some descriptive statistics of the six cryptocurrencies and the six stock market indices. We observe that the cryptocurrencies have higher returns but much higher volatility than the stock market indexes. In particular, Tether shows about $10^{4}$ differences between the minimum and maximum values, in comparison to the stock market indices. Moreover, the coefficient is dramatically higher in the cryptocurrencies (between 0.01 for Stellar, and 1.66 for Litecoin) than in the stock market indices (between 0.02 and 0.3 ), indicating a great dispersion in the cryptocurrency values. 


\section{Empirical results}

We start this section by considering the following model,

$$
\mathrm{y}_{\mathrm{t}}=\beta_{0}+\beta_{1} t+x_{\mathrm{t}} ; \quad(1-L)^{d} x_{t}=u_{t}, \quad t=0,1, \ldots,
$$

where $y_{t}$ refers to each of the time series we observe (in logs), $\beta_{0}$ and $\beta_{1}$ refers respectively to the intercept and a linear time trend; $x_{t}$ is supposed to be $I(d)$ and thus, $u_{t}$ is $I(0)$, and $d$ is a real value that is estimated from the data.

Across Tables $2-7$ we report the estimates of $d$ using the Whittle function in the frequency domain (Dahlhaus, 1989). Based on the nonstationary nature of the data examined, the analysis was conducted in the first differenced data, adding then the value 1 to obtain the estimated value of $d$. Moreover, we present in the table the interval of values of $d$ where the null hypothesis of $d$ being equal to a given value (say, $d_{o}$ ) cannot be rejected at the $5 \%$ level using a version of the tests of Robinson (1994), which is valid even in nonstationary contexts.

Table 2 displays the estimates of $d$ and the associated $95 \%$ confidence bands, in the model given by (2) under the assumption that $\mathrm{u}_{\mathrm{t}}$ is a white noise process. We display the results for the three common cases of i) no regressors, i.e., imposing that $\beta_{0}$ and $\beta_{1}$ are both equal to zero; ii) an intercept (i.e., with $\beta_{1}$ equal to 0 ); and iii) an intercept with a linear time trend (i.e., $\beta_{0}$ and $\beta_{1}$ estimated from the data), and mark in bold in the table the selected models according to these deterministic terms. Note that under the null hypothesis: $d=d_{o}$, equation (2) can be expressed as:

$$
(1-\mathrm{L})^{\mathrm{d}_{\mathrm{o}}} \mathrm{y}_{\mathrm{t}}=\beta_{0}(1-\mathrm{L})^{\mathrm{d}} \mathrm{o}_{1}+\beta_{1}(1-\mathrm{L})^{\mathrm{d}_{\mathrm{o}}}+u_{\mathrm{t}} ; \quad t=0,1, \ldots,
$$


and since $u_{t}$ is $I(0)$ by construction, t-tests apply on the coefficients $\beta_{0}$ and $\beta_{1}$. We see that for the cryptocurrencies, only the Bitcoin requires a linear time trend, and for the stock prices, the time trend is only required in the case of Standard and Poor (S\&P). In all other cases, the intercept is sufficient to describe the deterministic terms. Focusing on the estimated values of $\mathrm{d}$, and starting again with the cryptocurrencies, we observe that for Bitcoin and Ethereum, the unit root null hypothesis (i.e., $\mathrm{d}=1$ ) cannot be rejected; for Litecoin, Ripple and Stellar, the value of $\mathrm{d}$ is found to be significantly higher than 1 , and for Tether we get evidence in favour of mean reversion (i.e., $\mathrm{d}<1) .^{2}$ For the stock market, however, the results are more homogeneous and the unit root hypothesis cannot be rejected in any of the series with the exception of VIX where mean reversion is obtained. The evidence of mean reversion in the cases of Tether and VIX indicate that random shocks in these series have transitory though long lasting effects.

\section{[Insert Tables 2 and 3 about here]}

Table 3 extends the analysis to the case of autocorrelated errors. Here, instead of imposing a parametric ARMA model, we use a non-parametric approach due to Bloomfield (1973) that produces autocorrelations decaying exponentially as in the autoregressive (AR) case. One advantage of this model is that it is stationary for all its values unlike the AR case, and it accommodates very well in the context of fractional integration (Gil-Alana, 2004). Evidence of unit roots is now found in most of the cryptocurrencies; Bitcoin, Ethereum, Litecoin and Stellar; $\mathrm{d}>1$ is obtained for Ripple, and $\mathrm{d}<1$ (mean reversion) in the case of Tether, which is consistent with the results reported above for the white noise case. The findings on Tether is not surprising because, Tether (UST) mostly depicts a flat top price

\footnotetext{
${ }^{2}$ Note that Tether is $1: 1$ to the US dollar and has mostly shown a flat-top price development, being this potentially an argument to explain the mean reverting result.
} 
development since is only 1:1 to the US dollar. Hence the evidence of mean reversion (shock transitory) property was expected. For the stock market, the I(1) behaviour is found in all cases except Standard and Poor (S\&P 500) and VIX where the estimated value of $d$ is significantly below 1 .

We can summarize the results across these two tables by saying that evidence of unit roots is found in ${ }^{3}$ the majority of the series, and the only support of mean reversion is found in the cases of Tether for the cryptocurrencies, and VIX for the stock market prices.

Next we move to the multivariate work and look at the potential long run relationships between the cryptocurrencies, first by looking at vis-à-vis relationships between the variables. We consider two approaches here. First, we look at the differences in the log-values between the cryptocurrencies. We then conduct OLS regressions on each of the cryptocurrencies against the others, and estimate the value of $\mathrm{d}$ in the regression errors. The results are displayed respectively in Tables 4 and 5, and in both cases we consider the two cases of uncorrelated and autocorrelated errors.

\section{[Insert Tables 4 and 5 about here]}

Starting with the log-differences across the cryptocurrencies, in Table 4, we only observe a single case with evidence of mean reversion $(\mathrm{d}<1)$, this being the one corresponding to the difference between Ripple and Stellar. In all the other cases, the estimates of $d$ are in the I(1) intervals, finding evidence of no cointegration. Table 5 displays the estimates of the regression errors. We see that under no autocorrelation, mean reversion occurs in three cases related with Tether. This is not surprising, noting that Tether was the only cryptocurrency where mean reversion took place in the results displayed across Tables 2 and 3. If the errors

\footnotetext{
3 Thus, in both cases we test for (fractional) cointegration, assuming known values (1, -1) in the long run relationships in the first case, and estimating freely the coefficients in the second case. In the latter we use the approach in Engle and Granger (1987) though extended to the fractional case as in Cheung and Lai (1993) and Gil-Alana (2003).
} 
are autocorrelated, (Table 5) there are three more cases, dealing with Ripple, Litecoin and Stellar, though, in general, the orders of integration are relatively high and close to 1, implying once more, high degrees of persistence among the cryptocurrencies. The vast dispersion within the cryptocurrencies reported in this study could be accounted for using the findings of Osterrieder et al. (2017). These authors investigated statistical similarities and extreme value behavior of six virtual currencies. Their results suggest that the virtual currencies exhibit nonnormal statistical properties for those which share the same underlying technology. Accordingly, we surmise that the disconnections among cryptocurrencies could be as a result of the above reason. In addition, we link our findings of interdependence among cryptocurrencies to the fact that prices of cryptocurrencies fluctuate considerable wider than those of the standard fiat currencies (Dong et al., 2016). Our research suggests a role for cryptocurrencies in an investor portfolio, they being highly disconnected to each other and other mainstream assets. However, per the nature and price formation process of cryptocurrencies, the cryptocurrency market contains its own idiosyncratic risk that is extremely difficult to hedge against.

Next we focus on the relationships between the cryptocurrencies and the stock markets indices (Tables 6 and 7). As before, we look first at the differences in the log-values between the cryptocurrencies and the stock market prices following by OLS regressions of each of the variables against the others, and estimate the value of $\mathrm{d}$ in the regression errors. Results indicates that there is very little evidence of cointegration between the cryptocurrencies and the stock markets indices, which is consistent with Kurka (2017), Corbet et al. (2018), Liu and Tsyvniski (2018) and others.

[Insert Tables 6 and 7 about here] 
If we start with the log-differences, we observe that under no autocorrelation there is very little evidence of mean reversion, taking place only in case of the differences between Tether and the six stock market indices: Bond (0.76), Dollar (0.82), Gold (0.92), GSCI (0.93), S\&P (0.89), VIX (0.91). If the errors are autocorrelated, estimates of $\mathrm{d}$ significantly below 1 are observed in the differences between Bitcoin and VIX (0.90) and in the differences of Tether with Bond (0.76), Dollar (0.82).

For the case of the regression models, with the results reported across Table 7 , we observe some more cases of mean reversion, though once more the estimated values of $\mathrm{d}$ are relatively close to 1 . If there is no autocorrelation, we observe mean reversion in the regressions of Bitcoin against S\&P (0.93) and VIX (0.90); also with Ethereum against VIX (0.91); Litecoin against VIX (0.92) and in all cases with Tether against the six stock indices. With autocorrelation, mean reversion occurs in the same cases as before along with Ethereum against S\&P (0.91), Litecoin against S\&P (0.92) and Ripple against VIX (0.92). The above results connotes that cryptocurrencies and the selected financial and economic assets are disconnected. This suggests that for the period under study, financial market conditions influences cryptocurrencies less than structural conditions related to the design, price formation, operation and clearing of cryptocurrencies.

As a robustness method, and following the works by Mensi et al. (2018), OmaneAdjepong et al. (2019), Bouri et al. (2019) and others, the possibility of structural breaks is also taken into account, noting that the high levels of persistence obtained in the data could be a consequence of breaks which have not been taken into account (Diebold and Inoue, 2001; Granger and Hyung, 2004; etc.). Here, we focus on the six cryptocurrencies and examine the 
possibility of a single break in the data by using both Bai and Perron's (003) and Gil-Alana's (2008) methods, the latter being an extension of the former for the fractional case.

\section{[Insert Tables 8 and 9 about here]}

The results were identical in the two cases and the break date took place in all cases in 2017 at the time of the financial crisis, the specific dates ranging from 13 March 2017 (Ethereum) to 22 May 2017 (Tether). The results, however, were very similar to those presented above, finding evidence of unit roots in practically all cases, and the only evidence in favour of mean reversion is found in the cases of Stellar (during the first subsample) and Tether (especially during the second subsample). Based on these break dates, we reconduct the analysis among the cryptocurrencies and between the cryptocurrencies and the stock prices and the results were very similar to those obtained under no breaks, finding evidence of no cointegration in the majority of the cases.

\section{Summary and Concluding comments}

In this paper, we have examined the stochastic properties of six major cryptocurrencies and the bilateral linkages between six selected popular cryptocurrencies and six stock market indices, using daily prices. For the purposes of the study, we used a long memory approach based on fractionally integrated and cointegrated models. We adopted this approach to investigate the dependence between the selected markets since it allows for much richer dynamics than the classical models employed in recent studies on cryptocurrencies that focus exclusively on integer degrees of differentiation, and are thus based on the $\mathrm{I}(0) / \mathrm{I}(\mathrm{I})$ dichotomy.

The results from the univariate analysis indicate evidence of unit roots in most of the cryptocurrencies; Bitcoin, Ethereum, Litecoin and Stellar; $d>1$ is obtained for Ripple, and d $<1$ (mean reversion) in the case of Tether. Thus, only for this cryptocurrency will shocks have 
a transitory nature. For the stock market, I(1) behaviour is found in all cases except Standard and Poor (S\&P 500) and VIX, where the estimated value of $d$ is found to be significantly below 1. Nevertheless, the values are very high in all cases, supporting the evidence of high degrees of persistence. The fact that orders of integration close to 1 are found in the majority of the cases does not invalidate our results noting that they have been obtained under fractional alternatives rather than with the classical AR ones as is the case in all standard unit root methods. From the bivariate analysis, we document evidence of no cointegration between the six cryptocurrencies and very little evidence is found for cointegration between the cryptocurrencies and the selected stock markets indices. We document a very low level of connectedness between the six popular cryptocurrencies. We conclude that the cryptocurrency market is proving to be a more relevant phenomenon for financial markets than previously believed, due to the diversification option it offers investors because of the low level of connectedness with the traditional asset class.

The findings of this paper may have implications to investors, market participants and regulators. First, the low level of bilateral linkages between cryptocurrency market and stock indices found in this study may have implications on investor's choice of asset class to invest in, due to price independence. From a portfolio perspective, since price movements in the traditional asset class have no direct influence in the cryptocurrency market, investors or market participants can take capital and somehow invest in cryptocurrencies due to its inevitability benefits. The investability of cryptocurrencies and their accessibility around the world might drive more liquidity in the cryptocurrency markets than assets situated within boarders. Based on Bitcoin exchange trading volume averaging $\$ 1$ billion a day through the first quarter of 2016, we conclude that, in the coming years, liquidity in the cryptocurrency market will be compared more with traditional assets class since investors and market 
participants may be compelled to hold a cryptocurrency than an equity in a listed traded company. Second, focusing on the risk-reward profile shown in Table 1, what we see is that the traditional asset class recorded high level of risk and this implies that even though these markets may offer high returns to investors, due to their volatile nature, investors may be getting fewer returns for the risk they take on. Regarding the cryptocurrencies, they can be interpreted as independent financial instruments that pose little to no systematic risk, which may add to their attractiveness for investors. Third, concerning the connectedness within the cryptocurrency market, our findings of no cointegration within the cryptocurrencies provide insights for regulators and potential international investors. Owing to findings of this paper on the disparity among cryptocurrencies and disconnections between cryptocurrency and the traditional finance and economic asset class, what investors can do differently to cement the diversification benefits associated with their investments in cryptocurrencies is to call for policy makers and regulators to enact measures that will deepen the dispersed structural relations within the cryptocurrency market and with the rest of the traditional finance and economic asset class to ensure investors benefits with the diversification returns that comes with the disparity between cryptocurrency and stock market indices. As the literature grows, there are different valuation techniques to model and analysis the bilateral linkages between cryptocurrencies and traditional asset classes. Recently the use of copula to analyse financial markets data have become very popular. Hence, in future, we recommend the application of copula to uncover the connections between the studied asset classes in this study and provide grounds for further research since research on cryptocurrencies is at the experimental stage and requires more rigorous econometric techniques to establish stylized facts in the market. 


\section{References}

Aftab, M., Ahmad, R., \& Ismail, I. (2015). Dynamics between currency and equity in Chinese markets. Chinese Management Studies, 9(3), 333-354.

https://doi.org/10.1108/CMS-07-2014-0120.

Aysan, A. F., Demir, E., Gozgor, G., \& Lau, C. K. M. (2019). Effects of the geopolitical risks on Bitcoin returns and volatility. Research in International Business and Finance, 47, 511-518. https://doi.org/10.1016/j.ribaf.2018.09.011.

Baek, C., \& Elbeck, M. (2015). Bitcoins as an investment or speculative vehicle? A first look. Applied Economics Letters, 22(1), 30-34.

https://doi.org/10.1080/13504851.2014.916379.

Bai, J., and Perron. P., 2003. Computation and analysis of multiple structural change models. Journal of Applied Econometrics 18, 1-22.

https://doi.org/10.1002/jae.659.

Bariviera, A. F. (2017). The inefficiency of Bitcoin revisited: A dynamic approach. Economics Letters, 161, 1-4.

https://doi.org/10.1016/j.econlet.2017.09.013.

Bariviera, A. F., Zunino, L., \& Rosso, O. A. (2017). An analysis of high-frequency cryptocurrencies prices dynamics using permutation-information-theory quantifiers. Chaos: An Interdisciplinary Journal of Nonlinear Science, 28(7), 075511.

https://doi.org/10.1063/1.5027153.

Bartos, J. (2015). Does Bitcoin follow the hypothesis of efficient market?. International Journal of Economic Sciences, 4(2), 10-23.

DOI: 10.20472/ES.2015.4.2.002.

Beran, J., (1994), Statistics for long memory processes, Monographs on Statistics and Applied Probability 61, Chapman \& Hall.

ISBN 9780412049019.

Blau, B.M. (2018). Price dynamics and speculative trading in Bitcoin. Research in International Business and Finance 43, 15-21.

https://doi.org/10.1016/j.ribaf.2017.05.010.

Bloomberg, J. (2017), Japan's BITPoint to Add Bitcoin Payments to Retail Outlets. https://www.bloomberg.com/news/articles/2017-05-29/japan-s-bitpoint-to-add-bitcoinpayments-to-100-000s-of-outlets.

Bloomfield, P. (1973) An exponential model in the spectrum of a scalar time series, Biometrika, 60, 217-226. https://doi.org/10.1093/biomet/60.2.217.

Bouoiyour, J., \& Selmi, R. (2015). Bitcoin Price: Is it really that New Round of Volatility can be on way?. MPRA Paper 65580. University Library of Munich, Germany. https://ideas.repec.org/p/pra/mprapa/65580.html. 
Bouri, E., Gupta, R., \& Roubaud, D. (2018). Herding behaviour in cryptocurrencies. Finance Research Letters.

https://doi.org/10.1016/j.frl.2018.07.008.

Bouri, E., Lau, C. K. M., Lucey, B., \& Roubaud, D. (2018). Trading volume and the predictability of return and volatility in the cryptocurrency market. Finance Research Letters. https://doi.org/10.1016/j.frl.2018.08.015.

Bouri, E., Azzi, G., Dyhrberg, A.H., 2017. On the return-volatility relationship in the Bitcoin market around the price crash of 2013. Economics 11(2), 1-17.

http://dx.doi.org/10.5018/economics-ejournal.ja.2017-2.

Briere, M., Oosterlinck, K., \& Szafarz, A. (2015). Virtual currency, tangible return: Portfolio diversification with bitcoin. Journal of Asset Management, 16(6), 365-373. https://doi.org/10.1057/jam.2015.5.

Brown, W. L. (2014). An Analysis of Bitcoin Market Efficiency Through Measures of ShortHorizon Return Predictability and Market Liquidity. CMC Senior Theses. 864. https://scholarship.claremont.edu/cmc_theses/864.

Catania, L., \& Grassi, S. (2017). Modelling Crypto-Currencies Financial Time-Series. http://dx.doi.org/10.2139/ssrn.3028486.

Caporale, G. M., \& Plastun, A. (2018). The day of the week effect in the cryptocurrency market. Finance Research Letters.

https://doi.org/10.1016/j.frl.2018.11.012.

Caporale, G. M., Gil-Alana, L., \& Plastun, A. (2018). Persistence in the cryptocurrency market. Research in International Business and Finance, 46, 141-148. https://doi.org/10.1016/j.ribaf.2018.01.002.

Cheah, E. T., \& Fry, J. (2015). Speculative bubbles in Bitcoin markets? An empirical investigation into the fundamental value of Bitcoin. Economics Letters, 130, 32-36. https://doi.org/10.1016/j.econlet.2015.02.029.

Cheung, Y.W., Lai, K.S., 1993. A fractional cointegration analysis of purchasing power parity. Journal of Business and Economic Statistics 11, 103-112.

DOI: $10.2307 / 1391310$.

Cheung, A., Roca, E., \& Su, J. J. (2015). Crypto-currency bubbles: an application of the Phillips-Shi-Yu (2013) methodology on Mt. Gox bitcoin prices. Applied Economics, 47(23), 2348-2358.

DOI: $10.1080 / 00036846.2015 .1005827$.

Cointelegraph, (2017), South Korea Officially Legalizes Bitcoin, Huge Market For Traders. https://cointelegraph.com/news/south-korea-officially-legalizes-bitcoin-huge-market-for$\underline{\text { traders. }}$. 
Corbet, S., Meegan, A., Larkin, C., Lucey, B., \& Yarovaya, L. (2018). Exploring the dynamic relationships between cryptocurrencies and other financial assets. Economics Letters, 165, 2834.

https://doi.org/10.1016/j.econlet.2018.01.004.

Dahlhaus, R., (1989). Efficient parameter estimation for self-similar processes. Annals of Statistics. 17, 1749-1766.

DOI:10.1214/aos/1176347393.

Diebold F.X. and A. Inoue. 2001. Long memory and regime switching. Journal of Econometrics, 105: 131-159. https://doi.org/10.1016/S0304-4076(01)00073-2

Dong, H., Habermeier, K., Leckow, R., Haksar, V., Almeida, Y., Kashima, M., \& VerdugoYepes, C. (2016). IMF STAFF DISCUSSION NOTE: Virtual Currencies and Beyond: Initial Considerations. INTERNATIONAL MONETARY FUND Monetary and Capital Markets, Legal, and Strategy and Policy Review Departments. https://www.jdcoin.us/images/sdn1603.pdf

Dwyer, G. P. (2015). The economics of Bitcoin and similar private digital currencies. Journal of Financial Stability, 17, 81-91. https://doi.org/10.1016/j.jfs.2014.11.006.

Dyhrberg, A. H. (2016). Bitcoin, gold and the dollar-A GARCH volatility analysis. Finance Research Letters, 16, 85-92. https://doi.org/10.1016/j.frl.2015.10.008.

Eisl, A., Gasser, S., \& Weinmayer, K. (2015). Caveat emptor: does Bitcoin improve portfolio diversification?. http://dx.doi.org/10.2139/ssrn.2408997

Engle, R.F. and C.W.J. Granger (1987) Co-Integration and Error Correction: Representation, Estimation, and Testing, Econometrica 55, 2, 251-276. DOI: 10.2307/1913236.

Enterprise Ethereum Alliance (https://entethalliance.org/)

Feder A., Gandal N., Hamrick J.T., Moore T., Vasek M. (2018). The Rise and Fall of Cryptocurrencies, In Proc. of the Workshop on the Economics of Information Security (WEIS) (2018).

Forbes, (2017), Emerging Applications For Blockchain.

Fry, J., \& Cheah, E. T. (2016). Negative bubbles and shocks in cryptocurrency markets. International Review of Financial Analysis, 47, 343-352. https://doi.org/10.1016/j.irfa.2016.02.008.

Gandal, N., \& Halaburda, H. (2014). Competition in the cryptocurrency market. CEPR Discussion Paper No. DP10157. http://dx.doi.org/10.2139/ssrn.2506463.

Gil-Alana,L.A. (2003), Testing of Fractional Cointegration in Macroeconomic Time Series, Oxford Bulletin of Economics and Statistics 65, 4, 517-529. https://doi.org/10.1111/14680084.t01-1-00048. 
Gil-Alana, L. A. (2004) The use of the Bloomfield (1973) model as an approximation to ARMA processes in the context of fractional integration, Mathematical and Computer Modelling, 39: 429-436. https://doi.org/10.1016/S0895-7177(04)90515-8.

Gil-Alana, L. A. (2008). Fractional integration and structural breaks at unknown periods of time. Journal of Time Series Analysis 29, 163-185.

https://doi.org/10.1111/j.14679892.2007.00550.x.

Gil-Alana, L. A., \& Hualde, J. (2009). Fractional integration and cointegration: an overview and an empirical application. In Palgrave Handbook of Econometrics (pp. 434-469). Palgrave Macmillan, London. https://doi.org/10.1057/9780230244405_10.

Glaser, F., Zimmermann, K., Haferkorn, M., Weber, M., \& Siering, M. (2014). Bitcoin-asset or currency? revealing users' hidden intentions. ECIS 2014 (Tel Aviv). Available at SSRN: https://ssrn.com/abstract=2425247.

Granger C.W.J and N. Hyung (2004). Occasional structural breaks and long memory with an application to the S\&P 500 absolute stock returns. Journal of Empirical Finance, 11: 399-421. https://doi.org/10.1016/j.jempfin.2003.03.001

Hafner, C.M. (2018). Testing for Bubbles in Cryptocurrencies with Time-Varying Volatility, Journal of Financial Econometrics, nby023. https://doi.org/10.1093/jjfinec/nby023.

Hileman, G., \& Rauchs, M. (2017). Global cryptocurrency benchmarking study. Cambridge Centre for Alternative Finance, 33. http://dx.doi.org/10.2139/ssrn.2965436.

Investing (www.investing.com)

Kapar, B., \& Olmo, J. (2019). An analysis of price discovery between Bitcoin futures and spot markets. Economics Letters, 174, 62-64. https://doi.org/10.1016/j.econlet.2018.10.031.

Katsiampa, P. (2017). Volatility estimation for Bitcoin: A comparison of GARCH models. Economics Letters, 158, 3-6.

https://doi.org/10.1016/j.econlet.2017.06.023.

Kim, T. (2017). On the transaction cost of Bitcoin. Finance Research Letters, 23, 300-305. https://doi.org/10.1016/j.frl.2017.07.014.

Kurka, J.(2019). Do Cryptocurrencies and Traditional Asset Classes Influence Each Other? Finance Research Letters 31, 38-46.

https://doi.org/10.1016/j.frl.2019.04.018.

Kurihara, Y., \& Fukushima, A. (2017). The market efficiency of Bitcoin: a weekly anomaly perspective. Journal of Applied Finance and Banking, 7(3), 57-64.

ISSN: 1792-6580 (print version), 1792-6599 (online).

Liu, W. (2018). Portfolio diversification across cryptocurrencies. Finance Research Letters. https://doi.org/10.1016/j.frl.2018.07.010. 
Liu, Y., \& Tsyvinski, A. (2018). Risks and returns of cryptocurrency, NBER, National Bureau of Economic Research. Working Paper No. 24877.

http://dx.doi.org/10.2139/ssrn.3226952.

Nadarajah, S., \& Chu, J. (2017). On the inefficiency of Bitcoin. Economics Letters, 150, 6-9. https://doi.org/10.1016/j.econlet.2016.10.033.

Nakamoto, S. (2008). Bitcoin: A peer-to-peer electronic cash system. Cryptography Mailing list at https://metzdowd.com.

Omane-Adjepong, M., Alagidede, P., \& Akosah, N. K. (2019). Wavelet time-scale persistence analysis of cryptocurrency market returns and volatility. Physica A: Statistical Mechanics and its Applications, 514, 105-120.

https://doi.org/10.1016/j.physa.2018.09.013.

Omane-Adjepong, M., Ababio, K.A., Alagidede, I.P., 2019. Time-frequency analysis of behaviorally classified financial asset markets. Research in International Business and Finance 50, 54-69.

https://doi.org/10.1016/j.ribaf.2019.04.012.

Osterrieder, J., Strika, M., \& Lorenz, J. (2017). Bitcoin and Cryptocurrencies; ${ }^{a}$ Not for the Faint-Hearted. International Finance and Banking, 4(1), 56-94. https://doi.org/10.21256/zhaw-5509

Phillip, A., Chan, J., \& Peiris, S. (2018). A new look at Cryptocurrencies. Economics Letters, 163, 6-9.

https://doi.org/10.1016/j.econlet.2017.11.020.

Robinson, P.M. (1994) Efficient tests of nonstationary hypotheses, Journal of the American Statistical Association 89, 1420-1437.

DOI: $10.2307 / 2291004$.

Stensås, A., Nygaard, M.F., Kyaw, K., Treepongkaruna, S., 2019. Can Bitcoin be a diversifier, hedge or safe haven tool?. Cogent Economics \& Finance, (In-press), p.1593072. https://doi.org/10.1080/23322039.2019.1593072.

Tiwari, A. K., Cunado, J., Gupta, R., \& Wohar, M. E. (2018). Volatility spillovers across global asset classes: Evidence from time and frequency domains. The Quarterly Review of Economics and Finance, 70, 194-202.

https://doi.org/10.1016/j.qref.2018.05.001.

Urquhart, A. 2016. The inefficiency of Bitcoin. Economics Letters 148, 80-82.

https://doi.org/10.1016/j.econlet.2016.09.019.

Urquhart, A. (2017). Price clustering in Bitcoin. Economics letters, 159, 145-148.

https://doi.org/10.1016/j.econlet.2017.07.035.

Vandezande, N. (2017). Virtual currencies under EU anti-money laundering law. Computer Law \& Security Review, 33(3), 341-353. https://doi.org/10.1016/j.clsr.2017.03.011. 
Vidal-Tomás, D., \& Ibañez, A. (2018). Semi-strong efficiency of Bitcoin. Finance Research Letters 27, 259-265. https://doi.org/10.1016/j.frl.2018.03.013

Yarovaya, L., Brzeszczyński, J., \& Lau, C. K. M. (2016). Intra-and inter-regional return and volatility spillovers across emerging and developed markets: Evidence from stock indices and stock index futures. International Review of Financial Analysis, 43, 96-114. https://doi.org/10.1016/j.irfa.2015.09.004.

Yermack D. (2015), Is bitcoin a real currency? An economic appraisal, Handbook of Digital Currency, Bitcoin, Innovation, Financial Instruments and Big Data, p. 31-43. https://doi.org/10.1016/B978-0-12-802117-0.00002-3 
Table 1: Descriptive statistics

\begin{tabular}{lcccc}
\hline \multicolumn{1}{c}{ Max. } & Min. & Mean & Std. Dev. \\
\hline Cryptocurrency Markets & & & & \\
\hline BITCOIN & 3490,0955 & 4002,46481 & 19114,2 & 210,49 \\
ETHEREUM & 47,6523608 & 66,510549 & 358,34 & 2,63 \\
LITECOIN & 0,24499567 & 0,40626048 & 3,2 & 0,00409 \\
RIPPLE & 0,08696606 & 0,14483281 & 0,896227 & 0,001444 \\
STELLAR & 0,99970524 & 0,0105739 & 1,08 & 0,913595 \\
TETHER & 214,180368 & 282,52745 & 1299,74 & 0,434829 \\
\hline Stock Market Indices & & & & \\
BOND & 2359,26414 & 297,162205 & 2930,75 & 1829,08 \\
DOLLAR & 2397,70915 & 234,867302 & 2956,024 & 1860,66 \\
GOLD & 14,5994915 & 4,55763708 & 40,74 & 9,14 \\
GSCI & 113,812594 & 2,2477448 & 118,768 & 109,0196 \\
S\&P & 664,321065 & 2,88546641 & 736,56 & 566,41 \\
VIX & 121,982824 & 38,5801712 & 129,0778 & 115,2109 \\
\hline
\end{tabular}

Figure 1: Descriptive statistics of the Cryptocurrency and Stock Market Indices.

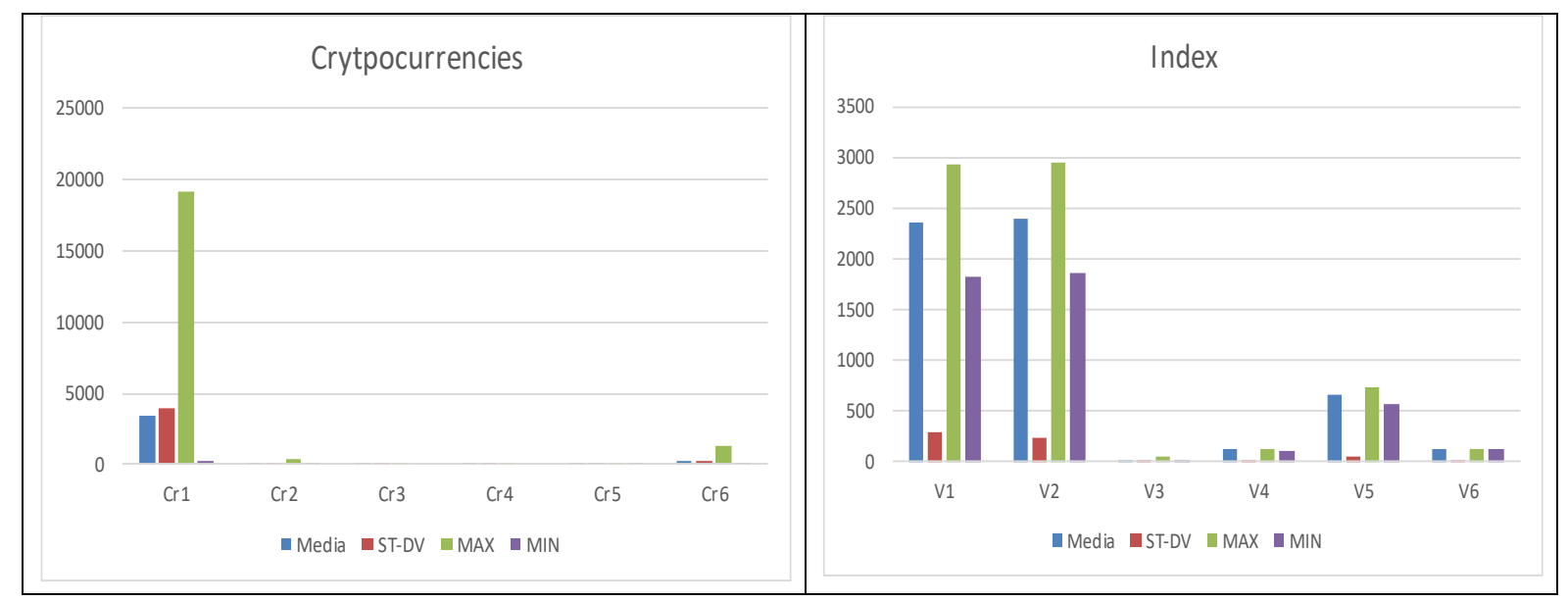


Table 2: Estimates of d based on uncorrelated (white noise) errors

i) Cryptocurrencies

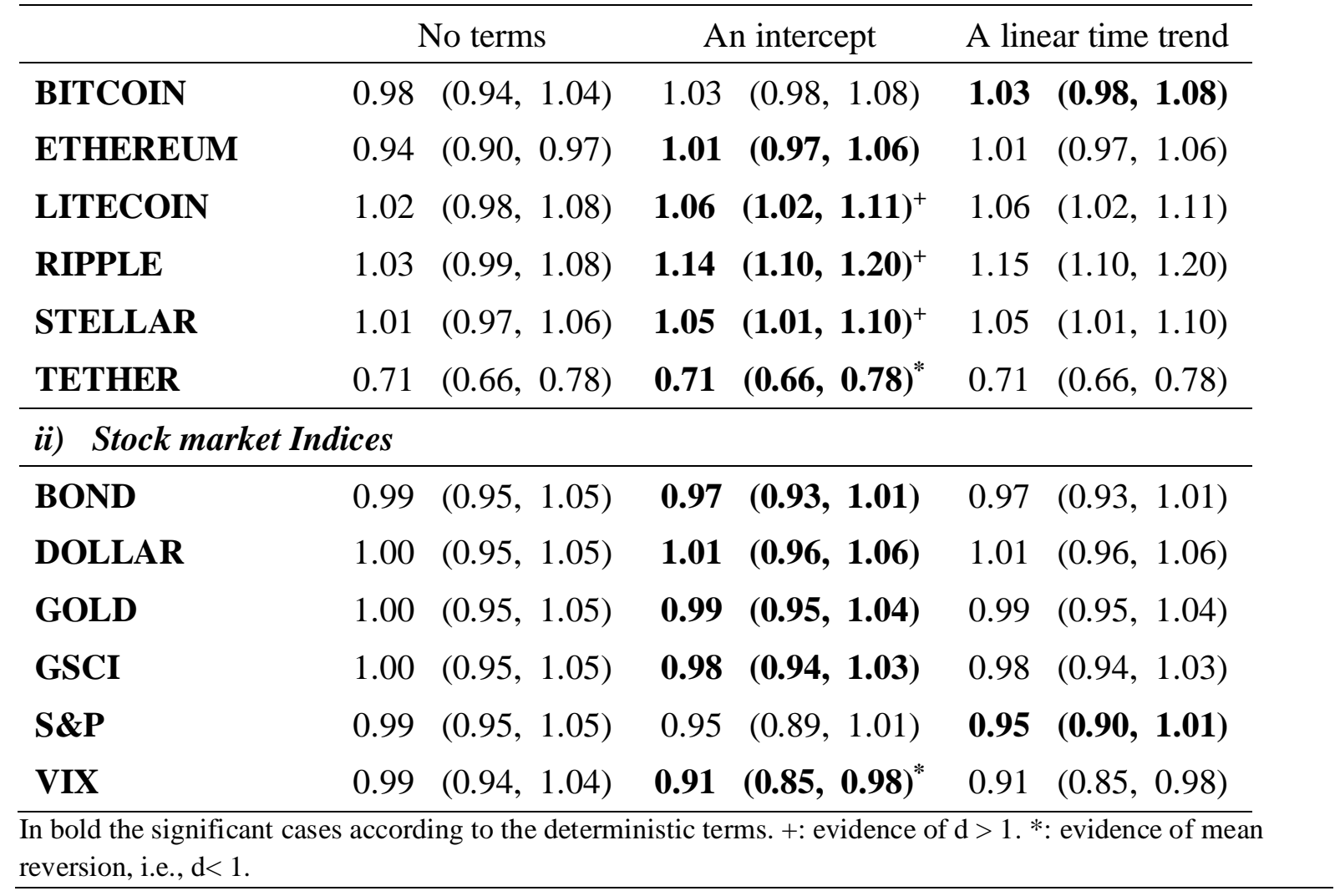


Table 3: Estimates of $\mathbf{d}$ based on autocorrelated (Bloomfield) errors

i) Cryptocurrencies

\begin{tabular}{lccccccc}
\hline & \multicolumn{2}{c}{ No terms } & \multicolumn{2}{c}{ An intercept } & \multicolumn{2}{c}{ A linear time } \\
\hline BITCOIN & 0.98 & $(0.91,1.08)$ & 1.04 & $(0.96,1.12)$ & $\mathbf{1 . 0 4}$ & $(\mathbf{0 . 9 6}, \mathbf{1 . 1 1})$ \\
ETHEREUM & 1.05 & $(0.99,1.12)$ & $\mathbf{1 . 0 1}$ & $\mathbf{( 0 . 9 6 , \mathbf { 1 . 0 7 } )}$ & 1.01 & $(0.96,1.07)$ \\
LITECOIN & 1.00 & $(0.93,1.09)$ & $\mathbf{1 . 0 2}$ & $(\mathbf{0 . 9 6}, \mathbf{1 . 1 0})$ & 1.02 & $(0.96,1.10)$ \\
RIPPLE & 1.05 & $(0.98,1.14)$ & $\mathbf{1 . 1 5}$ & $(\mathbf{1 . 0 8}, \mathbf{1 . 2 6})^{+}$ & 1.16 & $(1.08,1.26)$ \\
STELLAR & 1.02 & $(0.96,1.10)$ & $\mathbf{1 . 0 4}$ & $(\mathbf{0 . 9 8}, \mathbf{1 . 1 1})$ & 1.04 & $(0.98,1.11)$ \\
TETHER & 0.67 & $(0.57,0.81)$ & $\mathbf{0 . 6 7}$ & $(\mathbf{0 . 5 7}, \mathbf{0 . 8 1})^{*}$ & 0.67 & $(0.57,0.81)$ \\
\hline ii) $\quad$ Stock market indices & & & & & & \\
\hline BOND & 0.98 & $(0.92,1.07)$ & $\mathbf{1 . 0 5}$ & $(\mathbf{0 . 9 8}, \mathbf{1 . 1 3})$ & 1.05 & $(0.98,1.13)$ \\
DOLLAR & 0.99 & $(0.92,1.08)$ & $\mathbf{0 . 9 8}$ & $(\mathbf{0 . 9 2}, \mathbf{1 . 0 6})$ & 0.98 & $(0.92,1.06)$ \\
GOLD & 0.99 & $(0.92,1.08)$ & $\mathbf{1 . 0 4}$ & $(\mathbf{0 . 9 6}, \mathbf{1 . 1 3})$ & 1.04 & $(0.96,1.13)$ \\
GSCI & 0.99 & $(0.92,1.08)$ & $\mathbf{1 . 0 2}$ & $(\mathbf{0 . 9 3}, \mathbf{1 . 1 0})$ & 1.02 & $(0.93,1.10)$ \\
S\&P & 0.98 & $(0.92,1.08)$ & 0.88 & $(0.81,0.97)$ & $\mathbf{0 . 8 6}$ & $(\mathbf{0 . 7 8}, \mathbf{0 . 9 7})^{*}$ \\
VIX & 1.01 & $(0.93,1.09)$ & $\mathbf{0 . 7 8}$ & $(\mathbf{0 . 6 7}, \mathbf{0 . 8 8})$ & 0.78 & $(0.67,0.88)$ \\
\hline
\end{tabular}

In bold the significant cases according to the deterministic terms. + : evidence of $\mathrm{d}>1$. *: evidence of mean reversion, i.e., $\mathrm{d}<1$. 
Table 4: Estimates of d based on the differences between log-cryptocurrencies

i) No autocorrelation

\begin{tabular}{|c|c|c|c|c|c|c|}
\hline & BITCOIN & ETHEREUM & LITECOIN & RIPPLE & STELLAR & TETHER \\
\hline BITCOIN & --- & $\begin{array}{c}1.01 \\
(0.97,1.07)\end{array}$ & $\begin{array}{c}1.04 \\
(0.99,1.10)\end{array}$ & $\begin{array}{c}1.15 \\
(1.10,1.21)\end{array}$ & $\begin{array}{c}1.02 \\
(0.98,1.07)\end{array}$ & $\begin{array}{c}1.02 \\
(0.97,1.06)\end{array}$ \\
\hline ETHEREUM & --- & --- & $\begin{array}{c}1.01 \\
(0.96,1.07)\end{array}$ & $\begin{array}{c}1.03 \\
(0.98,1.10)\end{array}$ & $\begin{array}{c}0.99 \\
(0.93,1.05)\end{array}$ & $\begin{array}{c}1.01 \\
(0.97,1.06)\end{array}$ \\
\hline LITECOIN & --- & --- & --- & $\begin{array}{c}1.02 \\
(0.96,1.07)\end{array}$ & $\begin{array}{c}1.00 \\
(0.95,1.06)\end{array}$ & $\begin{array}{c}1.05 \\
(1.01,1.11)\end{array}$ \\
\hline RIPPLE & --- & --- & --- & --- & $\begin{array}{c}1.02 \\
(0.97,1.09)\end{array}$ & $\begin{array}{c}1.14 \\
(1.10,1.18)\end{array}$ \\
\hline STELLAR & --- & --- & --- & --- & -- & $\begin{array}{c}1.05 \\
(1.01,1.10)\end{array}$ \\
\hline \multicolumn{7}{|c|}{ ii) With autocorrelation } \\
\hline & BITCOIN & ETHEREUM & LITECOIN & RIPPLE & STELLAR & TETHER \\
\hline BITCOIN & --- & $\begin{array}{c}0.97 \\
(0.93,1.04)\end{array}$ & $\begin{array}{c}0.94 \\
(0.88,1.02)\end{array}$ & $\begin{array}{c}1.08 \\
(1.02,1.14)\end{array}$ & $\begin{array}{c}0.98 \\
(0.93,1.06)\end{array}$ & $\begin{array}{c}1.02 \\
(0.96,1.1)\end{array}$ \\
\hline ETHEREUM & --- & --- & $\begin{array}{c}0.94 \\
(0.88,1.01)\end{array}$ & $\begin{array}{c}0.93 \\
(0.87,1.01)\end{array}$ & $\begin{array}{c}0.94 \\
(0.89,1.01)\end{array}$ & $\begin{array}{c}1.01 \\
(0.96,1.07)\end{array}$ \\
\hline LITECOIN & --- & --- & --- & $\begin{array}{c}0.92 \\
(0.85,1.01)\end{array}$ & $\begin{array}{c}0.92 \\
(0.84,0.99)\end{array}$ & $\begin{array}{c}1.03 \\
(0.97,1.11)\end{array}$ \\
\hline RIPPLE & --- & --- & --- & --- & $\begin{array}{c}0.86^{*} \\
(0.80,0.94)\end{array}$ & $\begin{array}{c}1.15 \\
(1.08,1.24)\end{array}$ \\
\hline STELLAR & --- & --- & --- & --- & -- & $\begin{array}{c}1.03 \\
(0.98,1.11)\end{array}$ \\
\hline
\end{tabular}

*: Evidence of mean reversion at the $5 \%$ level. 
Table 5: Estimates of $d$ based on the regression errors of log-cryptocurrencies market prices

i) No autocorrelation

\begin{tabular}{lcccccc} 
& BITCOIN & ETHEREUM & LITECOIN & \multicolumn{2}{c}{ RIPPLE } & \multicolumn{2}{c}{ STELLAR } & TETHER \\
\hline BITCOIN & -- & 1.03 & 1.03 & 1.11 & 1.00 & $0.80^{*}$ \\
& & $(0.97,1.08)$ & $(0.98,1.08)$ & $(1.06,1.17)$ & $(0.96,1.06)$ & $(0.76,0.85)$ \\
ETHEREUM & --- & --- & 1.02 & 1.04 & 0.99 & $0.89^{*}$ \\
& & & $(0.97,1.10)$ & $(0.98,1.12)$ & $(0.95,1.05)$ & $(0.86,0.93)$ \\
LITECOIN & --- & --- & -- & 0.97 & 1.00 & $0.89^{*}$ \\
RIPPLE & --- & --- & -- & $(0.93,1.04)$ & $(0.95,1.06)$ & $(0.83,0.93)$ \\
STELLAR & --- & --- & --- & - & $(0.97,1.10)$ & $(0.93,1.02)$ \\
& & & & --- & -- & $0.87^{*}$ \\
ii) With autocorrelation & & & & & & \\
\hline
\end{tabular}

\begin{tabular}{lcccccc}
\hline & BITCOIN & ETHEREUM & LITECOIN & \multicolumn{2}{c}{ RIPPLE } & \multicolumn{2}{c}{ STELLAR } & TETHER \\
\hline BITCOIN & -- & 0.96 & 0.93 & 1.03 & 0.94 & $0.82^{*}$ \\
& & $(0.911 .03)$ & $(0.86,1.01)$ & $(0.96,1.11)$ & $(0.87,1.02)$ & $(0.77,0.89)$ \\
ETHEREUM & --- & --- & 0.94 & 0.94 & 0.94 & 0.96 \\
& & & $(0.88,1.01)$ & $(0.85,1.01)$ & $(0.89,1.01)$ & $(0.90,1.02)$ \\
LITECOIN & --- & --- & --- & $0.85^{*}$ & $0.88^{*}$ & 0.95 \\
& & --- & -- & $(0.77,0.94)$ & $(0.82,0.97)$ & $(0.87,1.01)$ \\
RIPPLE & -- & ---- & $0.86^{*}$ & 0.99 \\
& & --- & --- & --- & $(0.80,0.95)$ & $(0.92,1.05)$ \\
STELLAR & ---- & $0.89^{*}$ \\
& & - & & - & & \\
\end{tabular}

*: Evidence of mean reversion at the $5 \%$ level. 
Table 6: Estimates of $d$ based on the differences between log-cryptocurrencies and logstock market prices

\begin{tabular}{lcccccc} 
i) No autocorrelation & & & & & \\
\hline & BOND & DOLLAR & GOLD & GSCI & S\&P & VIX \\
\hline BITCOIN & 1.02 & 1.02 & 1.03 & 1.03 & 1.01 & 0.98 \\
& $(0.98,1.07)$ & $(0.98,1.07)$ & $(0.99,1.08)$ & $(0.98,1.08)$ & $(0.97,1.06)$ & $(0.93,1.04)$ \\
ETHEREUM & 1.01 & 1.01 & 1.00 & 1.01 & 1.01 & 1.00 \\
& $(0.97,1.06)$ & $(0.97,1.06)$ & $(0.96,1.05)$ & $(0.97,1.06)$ & $(0.96,1.06)$ & $(0.95,1.06)$ \\
LITECOIN & 1.06 & 1.06 & 1.06 & 1.06 & 1.05 & 1.03 \\
& $(1.01,1.11)$ & $(1.02,1.11)$ & $(1.02,1.12)$ & $(1.01,1.11)$ & $(1.01,1.11)$ & $(0.98,1.09)$ \\
RIPPLE & 1.14 & 1.15 & 1.14 & 1.14 & 1.14 & 1.07 \\
& $(1.10,1.20)$ & $(1.10,1.20)$ & $(1.10,1.19)$ & $(1.10,1.19)$ & $(1.10,1.20)$ & $(1.02,1.12)$ \\
STELLAR & 1.05 & 1.05 & 1.05 & 1.05 & 1.05 & 1.02 \\
& $(1.01,1.10)$ & $(1.01,1.10)$ & $(1.01,1.10)$ & $(1.01,1.10)$ & $(1.00,1.10)$ & $(0.97,1.07)$ \\
TETHER & $0.76^{*}$ & $0.82^{*}$ & $0.92^{*}$ & $0.93^{*}$ & $0.89^{*}$ & $0.91^{*}$ \\
& $(0.72,0.81)$ & $(0.77,0.87)$ & $(0.88,0.97)$ & $(0.89,0.98)$ & $(0.83,0.94)$ & $(0.85,0.98)$ \\
\hline \multirow{2}{*}{ With autocorrelation } & & & & & \\
\hline & BOND & DOLLAR & GOLD & GSCI & S\&P & VIX \\
\hline BITCOIN & 1.03 & 1.03 & 1.05 & 1.02 & 1.02 & $0.90^{*}$ \\
& $(0.97,1.12)$ & $(0.97,1.11)$ & $(0.97,1.12)$ & $(0.96,1.10)$ & $(0.96,1.10)$ & $(0.83,0.99)$ \\
ETHEREUM & 1.01 & 1.02 & 1.01 & 1.01 & 1.01 & 0.97 \\
& $(0.96,1.07)$ & $(0.97,1.08)$ & $(0.96,1.07)$ & $(0.96,1.07)$ & $(0.96,1.06)$ & $(0.92,1.04)$ \\
LITECOIN & 1.03 & 1.03 & 1.03 & 1.03 & 1.02 & 0.96 \\
& $(0.96,1.09)$ & $(0.98,1.11)$ & $(0.96,1.11)$ & $(0.96,1.10)$ & $(0.96,1.09)$ & $(0.90,1.06)$ \\
RIPPLE & 1.17 & 1.16 & 1.16 & 1.15 & 1.17 & 1.04 \\
& $(1.10,1.26)$ & $(1.08,1.26)$ & $(1.09,1.25)$ & $(1.08,1.25)$ & $(1.10,1.25)$ & $(0.96,1.13)$ \\
STELLAR & 1.04 & 1.04 & 1.05 & 1.03 & 1.03 & 0.98 \\
& $(0.98,1.11)$ & $(0.98,1.11)$ & $(0.98,1.13)$ & $(0.96,1.11)$ & $(0.97,1.11)$ & $(0.92,1.07)$ \\
TETHER & $0.79^{*}$ & $0.85^{*}$ & 0.98 & 0.98 & $0.86^{*}$ & $0.78^{*}$ \\
& $(0.71,0.89)$ & $(0.77,0.95)$ & $(0.90,1.09)$ & $(0.87,1.05)$ & $(0.77,0.95)$ & $(0.67,0.89)$ \\
\hline
\end{tabular}

*: Evidence of mean reversion at the $5 \%$ level. 
Table 7: Estimates of $d$ based on the regression errors of log-cryptocurrencies on logstock market prices

\begin{tabular}{lcccccc}
\hline i) & No autocorrelation & & & & \\
\hline & BOND & DOLLAR & GOLD & GSCI & S\&P & VIX \\
\hline BITCOIN & 1.03 & 1.04 & 1.02 & 0.99 & $0.93^{*}$ & $0.90^{*}$ \\
& $(0.99,1.08)$ & $(0.99,1.10)$ & $(0.97,1.07)$ & $(0.95,1.05)$ & $(0.88,0.98)$ & $(0.85,0.96)$ \\
ETHEREUM & 1.02 & 0.96 & 0.95 & 0.99 & 0.95 & $0.91^{*}$ \\
& $(0.97,1.06)$ & $(0.91,1.02)$ & $(0.91,1.01)$ & $(0.95,1.04)$ & $(0.89,1.00)$ & $(0.85,0.97)$ \\
LITECOIN & 1.06 & 1.04 & 1.02 & 1.00 & 0.96 & $0.92^{*}$ \\
& $(1.01,1.10)$ & $(0.98,1.10)$ & $(0.97,1.08)$ & $(0.96,1.06)$ & $(0.91,1.02)$ & $(0.87,0.97)$ \\
RIPPLE & 1.10 & 1.06 & 1.04 & 1.04 & 1.03 & 0.97 \\
& $(1.06,1.15)$ & $(1.01,1.11)$ & $(1.00,1.09)$ & $(0.99,1.09)$ & $(0.98,1.09)$ & $(0.92,1.03)$ \\
STELLAR & 1.03 & 1.02 & 1.02 & 0.99 & 0.98 & 0.97 \\
& $(0.98,1.08)$ & $(0.97,1.07)$ & $(0.98,1.07)$ & $(0.95,1.05)$ & $(0.93,1.03)$ & $(0.93,1.03)$ \\
TETHER & $0.71^{*}$ & $0.71^{*}$ & $0.71^{*}$ & $0.71^{*}$ & $0.71^{*}$ & $0.71^{*}$ \\
& $(0.66,0.78)$ & $(0.66,0.78)$ & $(0.66,0.78)$ & $(0.66,0.77)$ & $(0.66,0.78)$ & $(0.66,0.77)$ \\
\hline ii) With autocorrelation & & & & & \\
\hline & BOND & DOLLAR & GOLD & GSCI & S\&P & VIX \\
\hline BITCOIN & 1.06 & 0.97 & 1.06 & 1.00 & $0.87^{*}$ & $0.79^{*}$ \\
& $(1.00,1.13)$ & $(0.89,1.07)$ & $(0.99,1.17)$ & $(0.94,1.09)$ & $(0.79,0.94)$ & $(0.69,0.88)$ \\
ETHEREUM & 1.03 & 0.92 & 1.00 & 1.02 & $0.91^{*}$ & $0.81^{*}$ \\
& $(0.98,1.08)$ & $(0.87,1.01)$ & $(0.92,1.09)$ & $(0.96,1.08)$ & $(0.85,0.98)$ & $(0.70,0.89)$ \\
LITECOIN & 1.05 & 0.94 & 1.05 & 1.01 & $0.92^{*}$ & $0.84^{*}$ \\
& $(1.00,1.12)$ & $(0.83,1.02)$ & $(0.97,1.13)$ & $(0.95,1.10)$ & $(0.85,0.99)$ & $(0.79,0.92)$ \\
RIPPLE & 1.13 & 1.05 & 1.08 & 1.05 & 1.00 & $0.92^{*}$ \\
& $(1.06,1.21)$ & $(0.97,1.14)$ & $(1.01,1.18)$ & $(0.98,1.12)$ & $(0.93,1.08)$ & $(0.82,0.99)$ \\
STELLAR & 1.04 & 0.97 & 1.08 & 1.00 & $0.91^{*}$ & 0.93 \\
& $(0.97,1.11)$ & $(0.86,1.04)$ & $(1.01,1.16)$ & $(0.93,1.10)$ & $(0.84,0.99)$ & $(0.87,1.01)$ \\
TETHER & $0.68^{*}$ & $0.67^{*}$ & $0.67^{*}$ & $0.68^{*}$ & $0.67^{*}$ & $0.67^{*}$ \\
& $(0.56,0.80)$ & $(0.57,0.80)$ & $(0.57,0.79)$ & $(0.57,0.80)$ & $(0.57,0.80)$ & $(0.57,0.80)$ \\
\hline
\end{tabular}

*: Evidence of mean reversion at the $5 \%$ level. 
Table 8: Estimates of $d$ under the presence of a single break. White noise errors

\begin{tabular}{lccccc} 
& \multicolumn{1}{c}{ Break date } & \multicolumn{2}{c}{$1^{\text {st }}$ sub-sample } & \multicolumn{2}{c}{$2^{\text {nd }}$ sub-sample } \\
\hline BITCOIN & $01-05-2017$ & 0.96 & $(0.89,1.04)$ & 1.05 & $(0.98,1.12)$ \\
ETHEREUM & $13-03-2017$ & 0.93 & $(0.88,1.01)$ & 1.07 & $(1.01,1.15)$ \\
LITECOIN & $03-04-2017$ & 0.96 & $(0.89,1.04)$ & 1.08 & $(1.01,1.17)$ \\
RIPPLE & $31-03-2017$ & 1.05 & $(0.97,1.14)$ & 1.12 & $(1.06,1.19)$ \\
STELLAR & $28-04-2017$ & $0.83^{*}$ & $(0.77,0.91)$ & 1.08 & $(1.02,1.16)$ \\
TETHER & $22-05-2017$ & 1.09 & $(0.98,1.22)$ & $0.42^{*}$ & $(0.35,0.51)$ \\
*: Evidence of mean reversion at the $95 \%$ level. & & & & & \\
\hline
\end{tabular}

Table 9: Estimates of $d$ under the presence of a single break. Autocorrelated errors

\begin{tabular}{lccccc} 
& \multicolumn{1}{c}{ Break date } & \multicolumn{2}{c}{$1^{\text {st }}$ sub-sample } & \multicolumn{2}{c}{$2^{\text {nd }}$ sub-sample } \\
\hline BITCOIN & $01-05-2017$ & 0.90 & $(0.89,1.04)$ & 1.06 & $(0.96,1.17)$ \\
ETHEREUM & $13-03-2017$ & 0.93 & $(0.86,1.01)$ & 1.04 & $(0.95,1.14)$ \\
LITECOIN & $03-04-2017$ & 0.94 & $(0.76,1.12)$ & 0.98 & $(0.89,1.10)$ \\
RIPPLE & $31-03-2017$ & 0.98 & $(0.86,1.14)$ & 1.21 & $(1.10,1.35)$ \\
STELLAR & $28-04-2017$ & $0.78^{*}$ & $(0.69,0.91)$ & 1.03 & $(0.94,1.16)$ \\
TETHER & $22-05-2017$ & $0.63^{*}$ & $(0.52,0.77)$ & $0.38^{*}$ & $(0.26,0.57)$ \\
*: Evidence of mean reversion at the 95\% level. & & & & &
\end{tabular}

